Prolonged Time to Pregnancy in Female Workers Exposed to Ethylene Glycol Ethers in Semiconductor Manufacturing Author(s): Pau-Chung Chen, Gong-Yih Hsieh, Jung-Der Wang, Tsun-Jen Cheng Source: Epidemiology, Vol. 13, No. 2 (Mar., 2002), pp. 191-196

Published by: Lippincott Williams \& Wilkins

Stable URL: http://www.jstor.org/stable/3703912

Accessed: 07/04/2009 00:56

Your use of the JSTOR archive indicates your acceptance of JSTOR's Terms and Conditions of Use, available at http://www.jstor.org/page/info/about/policies/terms.jsp. JSTOR's Terms and Conditions of Use provides, in part, that unless you have obtained prior permission, you may not download an entire issue of a journal or multiple copies of articles, and you may use content in the JSTOR archive only for your personal, non-commercial use.

Please contact the publisher regarding any further use of this work. Publisher contact information may be obtained at http://www.jstor.org/action/showPublisher?publisherCode=lww.

Each copy of any part of a JSTOR transmission must contain the same copyright notice that appears on the screen or printed page of such transmission.

JSTOR is a not-for-profit organization founded in 1995 to build trusted digital archives for scholarship. We work with the scholarly community to preserve their work and the materials they rely upon, and to build a common research platform that promotes the discovery and use of these resources. For more information about JSTOR, please contact support@jstor.org. 


\title{
Prolonged Time to Pregnancy in Female Workers Exposed to Ethylene Glycol Ethers in Semiconductor Manufacturing
}

\author{
Pau-Chung Chen, ${ }^{1,2}$ Gong-Yih Hsieh, ${ }^{1}$ Jung-Der Wang, ${ }^{1,2}$ and Tsun-Jen Cheng ${ }^{1,2}$
}

\begin{abstract}
Background. Previous research on reproductive effects of working in the semiconductor industry is limited and has produced conflicting results.

Methods. This retrospective cohort study was designed to investigate the risk factors for female fertility in a wafermanufacturing company of Taiwan in 1997. Waiting time to pregnancy and potential confounders were collected by faceto-face interview. Exposure was assessed by directors and senior engineers in manufacturing, administrative, and safety and health departments according to safety records, personnel records, and job histories from questionnaires, using a tiered exposure-assessment approach. Of a total 842 female workers, $720(85.5 \%)$ participated. There were 292 pregnancies from
\end{abstract}

173 workers eligible for analysis. Relative fecundability (fecundability ratio, or FR) was calculated using Cox's proportional hazard models to evaluate the effect of occupational exposure to ethylene glycol ethers on female fertility.

Results. Waiting time to pregnancy of female workers in the photolithography area was longer than that of those in the nonfabrication area $(\mathrm{FR}=0.77 ; 95 \% \mathrm{CI}=0.45-1.32)$, and those who were potentially exposed to ethylene glycol ethers showed longer time to pregnancy compared with those not exposed ( $\mathrm{FR}=0.59 ; 95 \% \mathrm{CI}=0.37-0.94)$.

Conclusion. This study provides further evidence that ethylene glycol ethers may cause female subfertility. (EPIDEMIOLOGY 2002;13:191-196)

Key words: fecundability, occupational exposures, semiconductor manufacturing.

$\mathrm{T}$ here has been explosive growth of the semiconductor industry in Taiwan. Previous studies in the U.S. have suggested that certain exposures in this industry may impair female reproduction. Schenker and colleagues conducted a series of studies in the semiconductor industry, finding a moderate increase in risk of miscarriage and a reduction in fecundability. ${ }^{1-5}$ Among female manufacturers, Correa and colleagues found that potential exposure to mixtures containing ethylene glycol ethers (EGE) was associated with increased risks of miscarriage and subfertility. Both of these risks exhibited a dose-response relation with potential EGE exposure. ${ }^{6}$ In contrast, there was no evidence of an

From the 'Institute of Occupational Medicine and Industrial Hygiene, National Taiwan University College of Public Health, Taipei, Taiwan, ${ }^{2}$ Department of Internal Medicine, National Taiwan University Hospital, Taipei, Taiwan.

Address correspondence to: Pau-Chung Chen, Institute of Occupational Medicine and Industrial Hygiene, National Taiwan University College of Public Health, No.1, Section 1, Jen-Ai Road, Taipei, Taiwan; pcchen@ha.mc.ntu.edu.tw

This study was supported by the grant from National Health Research Institute, Department of Health, The Executive Yuan, Taiwan (DOH86-HR-504 and DOH87-HR-504).

Submitted February 3, 2000; final version accepted November 16, 2001.

Copyright @ 2002 by Lippincott Williams \& Wilkins, Inc. increased risk of miscarriage in the British semiconductor industry. ${ }^{?}$

The present study was conducted in Taiwan, which features a different culture, racial structure, and working practice than those of the U.S. and U.K. The objective of this study was to assess the effects of exposure to manufacturing processes or chemical agents on the fecundity of female workers in a semiconductor plant.

\section{Methods}

\section{Study Design and Subjects}

We conducted a retrospective cohort study of pregnancies between March 1990 and July 1997. Of a total 842 female workers, 720 agreed to be interviewed (a response rate of $85.5 \%)$. Among the participants, 242 workers reported 478 pregnancies. Sixty-nine females were excluded ( 57 with pregnancies conceived within 3 months of employment, 4 who smoked or consumed alcoholic beverages, and 8 with incomplete information), leaving 173 female workers with 292 pregnancies for the final analysis. The study was approved by the National Taiwan University College of Public Health 
TABLE 1. Numbers of Workers and Pregnancy Outcomes Among Mothers Working in Fabrication and Nonfabrication Rooms in a Semiconductor Factory in Taiwan

\begin{tabular}{|c|c|c|c|c|c|c|}
\hline \multirow[b]{2}{*}{ Response } & \multicolumn{5}{|c|}{ Fabrication } & \multirow[b]{2}{*}{ Nonfabrication } \\
\hline & Thin Film & Photolithography & Diffusion & Etching & Testing & \\
\hline Valid responses & 24 & 20 & 16 & 48 & 11 & 54 \\
\hline Valid pregnancies & 36 & 28 & 31 & 79 & 14 & 104 \\
\hline \multicolumn{7}{|l|}{ Pregnancy outcome } \\
\hline Time to pregnancy $>12$ months & 2 & 9 & 4 & 13 & 2 & 19 \\
\hline Twin live birth & 1 & - & - & 1 & - & 3 \\
\hline Stillbirth & - & 2 & 1 & - & - & - \\
\hline Miscarriage & 5 & $\overline{3}$ & 4 & 7 & - & 13 \\
\hline Hydatidi form mole & 1 & - & - & 1 & - & - \\
\hline Therapeutic abortion & 3 & 1 & 5 & 12 & 2 & 8 \\
\hline
\end{tabular}

Ethic Review Board and all study participants provided informed consent.

\section{Exposure Assessment}

Workers' exposure was assessed by a procedure similar to the three-tier approach used by Hammond et al. ${ }^{8} \mathrm{We}$ first conducted a hazard recognition assessment in each department of the factory and compiled a list of chemical inventory at different work areas and unit operations. Workers were classified into nonfabrication and fabrication groups; the latter group was further classified into thin film, photolithography, diffusion, etching, and testing work areas, and by potential exposure to EGE, arsenic, hydrogen fluoride, isopropanol, phosphorous compounds, radio-frequency, and $\mathrm{x}$-ray. Evaluations were based on workers' questionnaires regarding unit operations and work tasks performed, and verified by industrial hygienists during site visits. Exposure information was obtained without knowledge of time to pregnancy.

\section{Questionnaires}

We used a structured questionnaire to interview each female worker during July 1997. The content of the questionnaire included demographic data, life style, working history, psychiatric score, frequency of sexual intercourse before pregnancy, and detailed history of each pregnancy. Female interviewers conducted the interview in an isolated room to protect privacy.

We also used the Chinese Health Questionnaire, a questionnaire for screening of psychosocial stress. ${ }^{9}$ According to the validation studies of the Chinese Health Questionnaire, a score greater than or equal to four indicated some overt psychiatric symptoms, and so we categorized females into low (0), middle (1-3), and high $(\geq 4)$ stress levels. Time to pregnancy was defined as the duration between the dates of discontinuing contraceptive procedures and beginning of last menstrual period before pregnancy.

\section{Statistics}

Chi-square tests were applied to compare the demographic and health-related characteristics between fabrication and nonfabrication female workers. Fecundability denotes the probability of obtaining a clinically recognized pregnancy in a menstrual cycle among couples not pregnant in the previous cycles. The fecundability ratio (FR) measures the odds of a conception among the exposed divided by the odds among those not exposed. Fecundability ratios were calculated with $95 \%$ confidence intervals (CIs) using the Cox discrete proportional hazards regression ${ }^{10}$ to evaluate the effect on female workers in nonfabrication compared with fabrication work, as well as work area and potential exposure to chemical or physical agents. We included multiple pregnancies per couple, violating the assumption of independence and causing underestimation of the variance.

\section{Results}

There were 188 and 104 pregnancies in fabrication and nonfabrication workers, respectively. The overall rate of infertility (time to pregnancy more than 12 months) was slightly lower among fabrication workers $(16.0 \% ; 95 \% \mathrm{CI}=10.7-21.2 \%)$ than among nonfabrication workers $(18.3 \%$; $95 \% \mathrm{CI}=10.8-25.7 \%)$. Similarly, the miscarriage rate was slightly lower among fabrication workers $(10.1 \% ; 95 \% \mathrm{CI}=5.8-14.4 \%)$ than among nonfabrication workers $(12.5 \% ; 95 \% \mathrm{CI}=6.1$ $18.9 \%)$. Pregnancy outcomes of fabrication workers included three stillbirths and two hydatidiform moles, whereas nonfabrication workers had no such outcomes (Table 1). Therapeutic abortion was more frequent among fabrication workers $(12.2 \%)$ than nonfabrication workers (7.7\%).

Demographic and health related characteristics are summarized in Table 2. Forty-seven percent of workers were Hakkas, a unique ethnic group of "Han" Chinese 
TABLE 2. Characteristics of Mothers Working in Fabrication and Nonfabrication Rooms in a Semiconductor Factory in Taiwan and Crude Fecundability Ratios (FRs), Comparing Fabrication and Nonfabrication Mothers

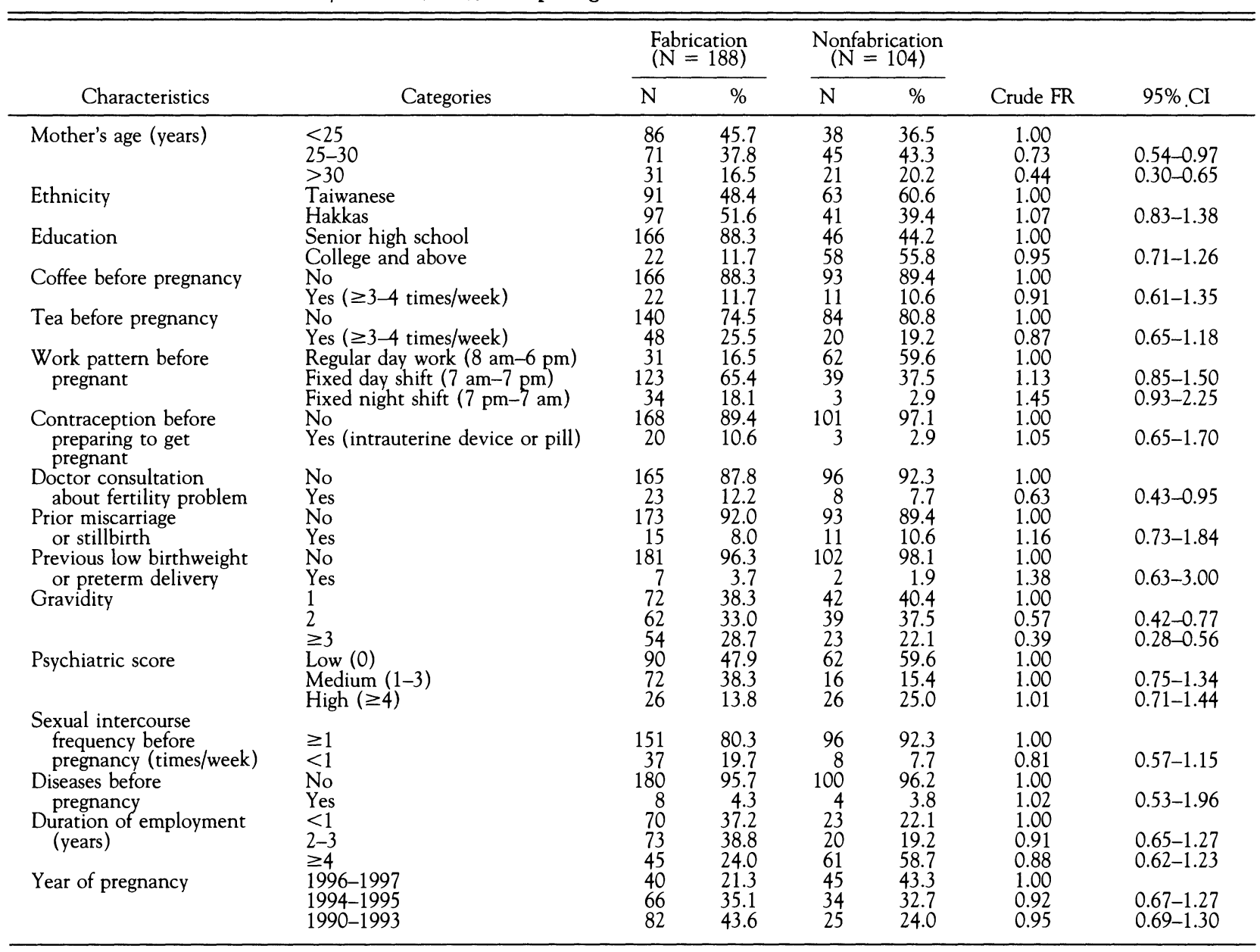

who are typically conservative and hardworking. Fabrication workers were younger and much less likely to have a college education compared with nonfabrication workers. Coffee and tea consumption were similar for these two groups. Fabrication workers were more likely to work the night shift, and less likely to have psychiatric complaints. Sexual intercourse before pregnancy was less frequent among fabrication workers. Duration of employment among fabrication workers was generally shorter than among nonfabrication workers.

Responses to questions about workers' husbands regarding demographic variables, smoking, alcohol drinking, working history, and past disease histories were similar for the fabrication and nonfabrication groups (data not shown).

Crude fecundability ratios of demographic and health-related characteristics are also shown on Table 2. Only mother's age, doctor consultation about a fertility problem, and gravidity were associated with reduced fecundability.

The results of Cox regression models for time to pregnancy are shown on Tables 3 and 4. When exposure was defined by work area, only females working in photolithography had reduced fecundability (adjusted FR = $0.77 ; 95 \% \mathrm{CI}=0.45-1.32$ ). There was, however, a marked reduction in fertility with exposure to ethylene glycol ethers (adjusted FR $=0.59 ; 95 \% \mathrm{CI}=0.37$ 0.94). In contrast, other specific hazards were associated with no change in fecundability.

\section{Discussion}

Exposure to ethylene glycol ethers (EGE) was associated with prolonged time to pregnancy in female fabrication workers. This association is plausibly causal. First, we dealt with variables that could have confounded the results. Workers with a history of uterine myoma, ${ }^{11}$ smoking, ${ }^{12,13}$ and alcohol drinking ${ }^{14,15}$ were excluded. Results were adjusted for other potential confounders, including mother's age ${ }^{16}$ prior miscarriage ${ }^{17}$ or stillbirth, previous low birth weight or preterm delivery, ${ }^{17,18}$ gravidity, ${ }^{19}$ psychiatric score, ${ }^{20}$ sexual intercourse frequency before pregnancy, contraception before pregnancy, and consultation about fertility problems. Second, EGE ex- 
TABLE 3. Crude and Adjusted Fecundability Ratios FRs) with $95 \%$ CIs of the Cox Regression Models for Time to Pregnancy of Female Workers at Different Manufacturing Areas in a Semiconductor Factory in Taiwan

\begin{tabular}{|c|c|c|c|c|c|c|}
\hline Exposure Variable & $\mathrm{N}$ & $\%$ & Crude FR & $95 \% \mathrm{CI}$ & Adjusted FR* & $95 \% \mathrm{CI}$ \\
\hline \multicolumn{7}{|l|}{ Work area } \\
\hline Nonfabrication & 104 & 35.6 & 1.00 & & 1.00 & \\
\hline Thin film & 36 & 12.3 & 1.56 & $0.99-2.44$ & 1.85 & $1.10-3.12$ \\
\hline Photolithography & 28 & 9.6 & 0.68 & $0.43-1.07$ & 0.77 & $0.45-1.32$ \\
\hline Diffusion & 31 & 10.6 & 1.32 & $0.84-2.09$ & 1.68 & $0.95-2.98$ \\
\hline Etching & 79 & 27.1 & 1.06 & $0.77-1.48$ & 1.44 & $0.94-2.21$ \\
\hline Testing & 14 & 4.8 & 1.17 & $0.62-2.19$ & 1.25 & $0.61-2.56$ \\
\hline \multicolumn{7}{|l|}{ Chemical agent } \\
\hline \multicolumn{7}{|l|}{ Ethylene glycol ethers } \\
\hline Unexposed & 264 & 90.4 & 1.00 & & 1.00 & \\
\hline Exposed & 28 & 9.6 & 0.62 & $0.41-0.94$ & 0.59 & $0.37-0.94$ \\
\hline
\end{tabular}

* Adjusted for mother's age, work pattern, contraception before preparing to get pregnant, gravidity, psychiatric score, sexual intercourse frequency before pregnancy, and duration of employment.

posure has previously been found to be associated with reduced fecundability in two groups of occupationallyexposed females. ${ }^{4,6}$ Animal studies in various species have shown embryonic ${ }^{21-23}$ and teratogenic ${ }^{21,24,25}$ toxicity with exposure to low airborne concentrations of ethylene glycol monomethyl ether (EGME).

Studies in nonhuman primates have demonstrated uniform distribution of the major metabolite of EGME, 2-methoxyacetic acid (2-MAA), in the embryo and extraembryonic fluids at a concentration similar to that in maternal serum..$^{23}$ The yolk sac, on the other hand, accumulated a very high concentration of 2-MAA. EGME and 2-MAA increased ovarian luteal cell progesterone production in the female rat in vivo and in cultured rat luteal cells in vitro, respectively. ${ }^{26}$ 2-MAA increased progesterone production in cultured human luteal cells at the same concentration as 2-MAA increased progesterone in rat luteal cells. ${ }^{27}$ These data suggest that EGME could affect reproductive endpoints in human females. EGME may target the ovary, and has the potential to alter ovarian luteal function. The precise mechanisms by which EGME causes reproductive damage remain unknown, but studies suggest that alkoxyacetic acids may interface with the formation of nucleic acids. ${ }^{28,29}$ Thus toxicity may be more apparent in tissues undergoing rapid cell proliferation, such as during embryogenesis and fetal development.

It is therefore biologically plausible that EGE could have toxic effects on human reproduction. We conclude that the prolonged time to pregnancy among females exposed to EGE was probably at least partially related to their exposure to EGE.

We also found three stillbirths and two hydatidiform moles among fabrication workers and none among nonfabrication workers. Chance must be considered as an explanation for these small numbers. The higher rate of therapeutic abortion among fabrication workers is also difficult to interpret. Induced abortion is widely practiced in Taiwan. The therapeutic abortion rate among the study subjects was much lower than the reported induced abortion rate in Taiwan 255 per 1000 pregnancies). ${ }^{30}$

Time to pregnancy was assessed using questionnaires as part of an annual health examination. Female workers with ailments were likely to miss the annual health examination or quit their jobs. The outcome was thus

TABLE 4. Crude and Adjusted Fecundability Ratios FRs) with 95\% Confidence Intervals CIs) of the Cox's Regression Models for Time to Pregnancy of Female Workers Potentially Exposed to Different Agents in a Semiconductor Factory in Taiwan

\begin{tabular}{|c|c|c|c|c|c|c|}
\hline Agent & $\mathrm{N}$ & $\%$ & Crude FR & $95 \% \mathrm{CI}$ & Adjusted FR* & $95 \% \mathrm{CI}$ \\
\hline \multicolumn{7}{|l|}{ Arsenic compound or $\mathrm{x}$-ray } \\
\hline Unexposed & 256 & 87.7 & 1.00 & & 1.00 & \\
\hline Exposed & 36 & 12.3 & 1.54 & $1.01-2.33$ & 1.48 & $0.93-2.37$ \\
\hline \multicolumn{7}{|l|}{ Hydrogen fluoride } \\
\hline Unexposed & 225 & 77.1 & 1.00 & & 1.00 & \\
\hline Exposed & 67 & 22.9 & 1.47 & $1.07-2.02$ & 1.45 & $1.00-2.10$ \\
\hline \multicolumn{7}{|l|}{ Isopropanol } \\
\hline $\begin{array}{l}\text { Unexposed } \\
\text { Exposed }\end{array}$ & 54 & 18.5 & $\begin{array}{l}1.00 \\
0.95\end{array}$ & $068-132$ & 1.00 & $085-216$ \\
\hline \multicolumn{7}{|l|}{ Phosphorous compounds } \\
\hline Unexposed & 235 & 80.5 & 1.00 & & 1.00 & \\
\hline Exposed & 57 & 19.5 & 1.50 & $1.07-2.10$ & 1.45 & $0.98-2.14$ \\
\hline \multicolumn{7}{|l|}{ Radio-frequency } \\
\hline Unexposed & 177 & 60.6 & 1.00 & & 1.00 & \\
\hline Exposed & 115 & 39.4 & 1.20 & $0.92-1.56$ & 1.30 & $0.93-1.81$ \\
\hline
\end{tabular}

* Adjusted for the same variables as in Table 3 and exposure to ethylene glycol ethers. 
underestimated owing to healthy worker effect. On the other hand, some female workers quit their jobs because of pregnancy whereas those who were infertile remained at work. This infertile worker effect ${ }^{31}$ could overestimate the outcome; however, only $4.0 \%$ of female workers in this study were concerned whether they were infertile. This rate is lower than the primary infertility rate $6.0 \%$ ) for the general population in Taiwan, ${ }^{32}$ reflecting that the time to pregnancy is not likely overestimated in this study.

Because we included more than one pregnancy per couple, the assumption of statistical independence was violated, potentially causing underestimation of the variance. Thus, we evaluated this potential bias by restricting the analysis to random, first, and last pregnancies. This restriction also helped us to avoid bias attributable to past adverse pregnancy outcomes. Although the numbers were small for each exposure group, results were consistent across all groups data not shown).

Workers may be exposed concurrently to multiple agents, and one agent may be used in multiple work areas. For this reason, it was difficult to evaluate the level of each exposure for each worker. This difficulty may introduce nondifferential misclassification of exposure and result in bias toward the null.

Stress has been associated with variation of menstrual cycle and anovulation. ${ }^{33}$ Hjollund and colleagues, ${ }^{20}$ however, did not find an association between stress and fecundability. Similarly, the stress measured by our psychiatric score was not associated with the fecundability of female workers in our study.

Although the frequency of intercourse is associated with probability of conception, it has been suggested that it is not essential to collect such information for studies of fecundability. ${ }^{34}$ If intercourse information is not available, this lack of information may obscure reproductive effects of an agent that affects the libido. Although we attempted to collect this information, we are concerned that the quality may be poor. Taiwan is a traditional Chinese culture in which the measurement of sexual life is difficult. Imprecision on these data will tend to produce nondifferential misclassification.

\section{Acknowledgment}

We thank Marc B. Schenker for helpful comments during the initiation of this study.

\section{References}

1. Schenker MB, Gold EB, Beaumont JJ, et al. Association of spontaneous abortion and other reproductive effects with work in the semiconductor industry. Am J Ind Med 1995;28:639-659.

2. Beaumont JJ, Swan SH, Hammond SK, et al. Historical cohort investigation of spontaneous abortion in the Semiconductor Health Study: epidemiologic methods and analyses of risk in fabrication overall and in fabrication work groups. Am J Ind Med 1995;28:735-750.

3. Swan SH, Beaumont JJ, Hammond SK, et al. Historical cohort study of spontaneous abortion among fabrication workers in the Semiconductor Health Study: agent-level analysis. Am J Ind Med 1995;28:751-769.

4. Eskenazi B, Gold EB, Samuels SJ, et al. Prospective assessment of fecundability of female semiconductor workers. Am J Ind Med 1995;28:817-831.

5. Eskenazi B, Gold EB, Lasley BL, et al. Prospective monitoring of early fetal loss and clinical spontaneous abortion among female semiconductor workers. Am J Ind Med 1995;28:833-846.

6. Correa A, Gray RH, Cohen R, et al. Ethylene glycol ethers and risks of spontaneous abortion and subfertility. Am J Epidemiol 1996;143:707-717.

7. Elliott RC, Jones JR, McElvenny DM, et al. Spontaneous abortion in the British semiconductor industry: an HSE investigation. Am J Ind Med 1999;36:557-572.

8. Hammond SK, Hines CJ, Hallock MF, et al. Tiered exposureassessment strategy in the Semiconductor Health Study. Am J Ind Med 1995;28:661-680.

9. Cheng TA, Williams P. The design and development of a screening questionnaire $\mathrm{CHQ}$ ) for use in community studies of mental disorders in Taiwan. Psychol Med 1986;16:415-422.

10. Scheike TH, Jensen TK. A discrete survival model with random effects: an application to time to pregnancy. Biometrics 1997;53: 318-329.

11. Lampe LG. Uterine surgery of sterility. Hum Reprod 1988;3:187192.

12. Bolumar F, Olsen J, Boldsen J. Smoking reduces fecundity: a European multicenter study on infertility and subfecundity. The European Study Group on Infertility and Subfecundity. Am J Epidemiol 1996;143:578-587.

13. Jensen TK, Henriksen TB, Hjollund NHI, et al. Adult and prenatal exposures to tobacco smoke as risk indicators of fertility among 430 Danish couples. Am J Epidemiol 1998;148:992-997.

14. Olsen J, Bolumar F, Boldsen J, et al. Does moderate alcohol intake reduce fecundability? A European multicenter study on infertility and subfecundity. European Study Group on Infertility and Subfecundity. Alcohol Clin Exp Res 1997;21:206-212.

15. Jensen TK, Hjollund NH, Henriksen TB, et al. Does moderate alcohol consumption affect fertility? Follow up study among couples planning first pregnancy. BMJ 1998;317:505-510.

16. Olsen J. Subfecundity according to the age of the mother and the father. Dan Med Bull 1990;37:281-282.

17. Joffe M, Li Z. Association of time to pregnancy and the outcome of pregnancy. Fertil Steril 1994;62:71-75.

18. Henriksen TB, Baird DD, Olsen J, et al. Time to pregnancy and preterm delivery. Obstet Gynecol 1997;89:594-599.

19. Tuntiseranee P, Olsen J, Chongsuvivatwong V, et al. Fecundity in Thai and European regions: results based on waiting time to pregnancy. Hum Reprod 1998;13:471-477.

20. Hjollund NHI, Jensen TK, Bonde JBE, et al. Job strain and time to pregnancy. Scand J Work Environ Health 1998;24:344-350.

21. Hardin BD, Bond GP, Sikov MR, et al. Testing of selected workplace chemicals for teratogenic potential. Scand J Work Environ Health 1981;7Suppl 4):66-75.

22. Nagano K, Nakayama E, Oobayashi H, et al. Embryotoxic effects of ethylene glycol monomethyl ether in mice. Toxicology 1981;20: 335-343.

23. Scott WJ, Fradkin R, Wittfoht W, et al. Teratologic potential of 2-methoxyethanol and transplacental distribution of its metabolite, 2-methoxyacetic acid, in non-human primates. Teratology 1989;39:363-373.

24. Hanley TR Jr, Young JT, John JA, et al. Ethylene glycol monomethyl ether EGME) and propylene glycol monomethyl ether 
PGME): inhalation fertility and teratogenicity studies in rats, mice and rabbits. Environ Health Perspect 1984;57:7-12.

25. Brown NA, Holt D, Webb M. The teratogenicity of methoxyacetic acid in the rat. Toxicol Lett 1984;22:93-100.

26. Davis BJ, Almekinder JL, Flagler N, et al. Ovarian luteal cell toxicity of ethylene glycol monomethyl ether and methoxy acetic acid in vivo and in vitro. Toxicol Appl Pharmacol 1997;142:328-337.

27. Almekinder JL, Lennard DE, Walmer DK, et al. Toxicity of methoxyacetic acid in cultured human luteal cells. Fundam Appl Toxicol 1997;38:191-194.

28. Stedman DB, Welsch F. Inhibition of DNA synthesis in mouse whole embryo culture by 2-methoxyacetic acid and attenuation of the effects by simple physiological compounds. Toxicol Lett 1989; 45:111-117.
29. Mebus CA, Welsch F. The possible role of one-carbon moieties in 2-methoxyethanol and 2-methoxyacetic acid-induced developmental toxicity. Toxicol Appl Pharmacol 1989;99:98-109.

30. Wang PD, Lin RS. Induced abortion in Taiwan. J R Soc Health 1995;115:100,105-108.

31. Joffe M. Biases in research on reproduction and women's work. Int J Epidemiol 1985;14:118-123.

32. Chang MC, Lin HS, Tsai YJ. Infertility Survey for Taiwan. Taichung: Taiwan Provincial Institute of Family Planning, 1997.

33. Harlow SD, Ephross SA. Epidemiology of menstruation and its relevance to women's health. Epidemiol Rev 1995;17:265-286.

34. Joffe M. Time to pregnancy: a measure of reproductive function in either sex. Asclepios Project. Occup Environ Med 1997;54:289295. 